\title{
Editorial
}

\section{The carcinogenicity of chromium and its salts}

There are some inherent difficulties when discussing metal carcinogenesis which are valid also for chromium and its salts. A metal cannot be classified as carcinogenic per se since its different compounds may have different potency. Exposure in metal processing and in the various industrial uses of metals is often complex and it is difficult epidemiologically to relate a carcinogenic effect to a single compound. Thus the carcinogenic risk must often be related to a process or to a group of metal compounds rather than to a single substance. Differences in carcinogenic potential are related not only to different chemical forms of the same metal but also to the particle size of the inhaled aerosol and to physical characteristics of the particle such as surface charges and crystal modification.

An increased risk for lung cancer has been clearly established in the primary chromate production industry and this has been attributed to exposure to an incompletely defined mixture of slightly soluble chromates from the roast and residue in the process. ${ }^{1}$ It has been claimed also that trivalent chromium compounds may constitute an increased risk but the epidemiological evidence is not conclusive. An increased risk has also been reported in workers predominently exposed in chromate production processes where exposure is mainly to soluble chromates, but there has always been some degree of mixed exposure. ${ }^{2}$

An excess risk of lung cancer has also been shown in the chrome pigment production industry. ${ }^{3-5}$ Workers in such plants are exposed not only to the slightly soluble zinc and lead chromates but also to soluble chromates. Whether exposure to lead chromate constitutes an increased risk has been a matter for discussion. Despite the limited solubility of this salt in buffer solutions, lead chromate exerts genetic toxicity in vitro and induces tumours at injection sites in experimental animals. ${ }^{67}$ Davies compared workers exposed to zinc chromate and lead chromate and found an increased risk for zinc chromate workers only, but she concludes on the basis of her results that lead chromate cannot be excluded as a risk factor. ${ }^{4}$ Both groups were apparently exposed to soluble chromates in the production process. An increased risk of cancer after exposure to lead chromate has, however, been shown by others. ${ }^{5}$
Of specific interest for the comparison of the carcinogenicity of soluble and insoluble or slightly soluble chromate compounds is the cancer risk in the plating industry because of the uniform exposure to soluble compounds. There are several reports from such industries but the results are generally inconclusive. ${ }^{1}$ Inconclusive and contradictory epidemiological studies have also been reported for painters and for workers in the ferro chromium industry. ${ }^{1}$ Welders are a large group with an interesting exposure pattern as are flame cutters and grinders, all of whom may be exposed to welding aerosols from stainless steel welding or from working with chromate primed materials. With stainless steel welding, about $70 \%$ of the total chromium in the aerosol is in the hexavalent form as soluble sodium or potassium monochromates, and such fume particles have been shown to be mutagenic. Langaard has recently reviewed several epidemiological studies carried out in welding populations, ${ }^{8}$ but conclusive results as to the carcinogenicity of chromium or chromium compounds in welding fumes could not be drawn.

The possibility that exposure to chromium compounds might cause cancer at sites other than the respiratory tract is a matter of discussion. Some results have been reported, but they can only be regarded as suggestive. ${ }^{1}$

The problems when discussing the carcinogenicity of chromium and its salts are whether both the hexavalent and trivalent form can cause cancer, which salts are active, and what is the importance of particle characteristics such as size, crystal modification, surface charge, solubility, or the ability to be phagocytised. The traditional answer to these questions, based on epidemiological evidence, is that only the chromates with limited solubility such as calcium chromate cause cancer. The conventional view is that the soluble chromates, the seemingly insoluble lead chromate and the trivalent chromium compounds, should not be regarded as carcinogens. ${ }^{1}$

Animal experiments have shed light on this problem to a limited degree. Malignant tumours have been reported after intramuscular and intraplural administration of mixed roasted chromate and after inhalation experiments in mice and rats using mixed 
chromate dust. ${ }^{18}$ In addition Nettesheim et al induced adenocarcinomas and adenomas in the bronchial tree in mice after inhalation exposure, ${ }^{9}$ and squamous cell carcinomas have been induced after bronchial instillation of calcium chromate and zinc potassium chromate. ${ }^{10}$

In short term tests, hexavalent chromium is the most active, inducing mutations in bacterial systems without prior activation. When the mutagenic property of soluble and slightly soluble chromates was compared in vitro no differences were found. ${ }^{11}$ The trivalent form has a limited mutagenic effect in such systems. Sirover and Loeb, however, showed that the trivalent form was more than 20 times as potent as the hexavalent form in decreasing the fidelity of DNA syntheses in vitro. ${ }^{12}$

Trivalent chromium may be the active carcinogenic agent within the cell, but it is inactive under practical conditions of exposure because it has a limited uptake. When bound to certain ligands, however, trivalent chromium may cross cell membranes, ${ }^{13-15}$ and the fact that trivalent chromium in some complex form is excreted in the bile also indicates its transport or passage. ${ }^{16}$ If hexavalent chromium is reduced outside the cell to the trivalent form, the genotoxic activity decreases. ${ }^{17}$ This may be related to uptake mechanisms, but it has recently been shown that even if trivalent chromium binds to rat DNA in vivo no lesions are detectable in the DNA by alkaline elution. Such lesions can be shown with similar chromium concentrations in DNA after exposure to the hexavalent form. ${ }^{15}$ Reduction inside the cell may thus be a prerequisite for genotoxic action by the generation of short lived, highly reactive chromium species. A limited uptake of trivalent chromium has been shown for mitochondria, but preliminary results suggest that this does not take place in the cell nucleus in vitro. ${ }^{18}$ This is an interesting aspect in the discussion of where in the cell reduction must take place to constitute a hazard for genetic material.

The discrepancy between the results with soluble and slightly soluble salts in vitro and under conditions of real exposure may be due to the rapid reduction of soluble salts outside the cell in the respiratory tract. More importantly, cancer induction may be related to a time dependent high local concentration of chromium in the cell caused by phagocytosis of a particle with subsequent dissolution. The epidemiological results may thus be explained by the fact that such high concentrations cannot be generated by the uptake of soluble salts. In vitro, the cells are continuously exposed from the medium, and phagocytosis is not a prerequisite.

Recently it has been reported that the cellular uptake of insoluble chromium oxide may cause cytotoxic and mutagenic effect in Chinese hamster cells. ${ }^{19}$
When compared with the negative mutagenicity tests of soluble trivalent chromium compounds in bacterial $\bar{a}$ test systems, ${ }^{20}$ this supports the theory that phago- $\bar{z}$ cytosis is necessary to establish a sufficiently high $\stackrel{\mathbb{Q}}{\odot}$ intercellular concentration of the active agent. Phagocytosis may also be important for hexavalent $\stackrel{\vec{\rho}}{\rightarrow}$ compounds since welding fume particles have been $\bar{C}$ shown to have a more pronounced effect than would be expected from the amount of soluble chromate in the medium. ${ }^{21}$ Corresponding results have been reported for nickel. ${ }^{22}$ Specific ligand binding seems to be important for the trivalent compounds as a series of hexacoordinate compounds have been shown to exert mutagenic effects in bacterial systems. ${ }^{13}$ These results appear to throw doubt on the concept that only hexavalent chromium compounds may cause cancer.

The question remains, however, as to whether a te sufficiently great intracellular concentration can be reached with soluble salts. We must assume that both the chromate ion (taken up as such) and the hexavalent ion generated after dissolution in the cell of a phagocytised particle are rapidly reduced to the trivalent form with binding to macromolecules. The equilibrium between dissolution, binding, and transport involves delicate biochemical mechanisms with several possible interactions. The transport is probably mediated by the phosphate pathway and by a $\overrightarrow{0}$ general anion pathway. ${ }^{18}$ Unpublished results from our laboratory show that intracellular glutathione depletion and anion transport inhibitors decrease the uptake in isolated liver cells. Increased phosphate in the medium decreases uptake, probably by competitive inhibition. Both sulphate and phosphate and increased glutathione in the medium decrease the mitochondrial uptake of chromate. The effect of glutathione is probably related to an increased reduction of the hexavalent form to the trivalent outside the organelle and possibly to increased protein binding.

The metabolism of chromate by cellular constituents has recently been extensively reviewed. ${ }^{23}$ Under physiological conditions the only small molecules that significantly reduce hexavalent chromium to the trivalent form are ascorbate and SH-containing substances such as cysteine and glutathione. Glutathione appears to be particularly important because of the high intracellular concentration. Proteins such as haemoglobin and glutathione reductase in the red cells have the same effect as does microsomal P-450 in the o liver cells; the mitochondria also reduce chromate. ${ }^{24} \mathrm{~N}$ It is important to note that there may be differences in the intracellular microkinetics of the trivalent form given as such if it penetrates into the cell and of the trivalent form after intracellular reduction of hexavalent chromium. ${ }^{1516}$ The reduction implies the gen- $\stackrel{\infty}{?}$

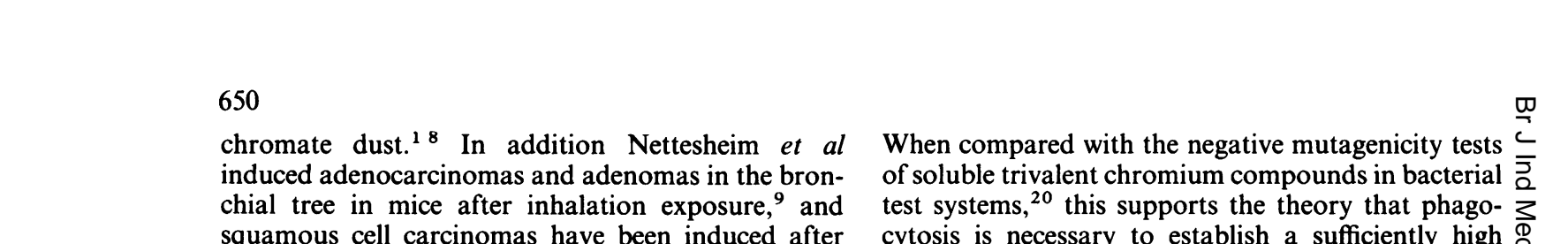


eration of short lived species of pentavalent and tetravalent chromium with chemical affinities that differ from those of the trivalent form. ${ }^{2325}$ The reduction process by itself may thus be important for the biological effects. The pattern of biliary excretion of trivalent chromium after injection compared with that after injection of the hexavalent form also supports such theories. ${ }^{16}$ Similar results have been reported by others investigating the complex formed between EDTA and trivalent chromium. ${ }^{25}$ The presence of glutathione increases the binding of chromium to haemoglobin after reduction of the hexavalent form. ${ }^{22}$

It was previously thought that the carcinogenic agent within the cell was the trivalent form generated by reduction of the hexavalent form after penetration into the cell. Exposure to the trivalent form was not regarded as a hazard because of lack of transport through biological membranes. The carcinogenic effect may not, however, be caused by the trivalent form proper but by some form of reactive intermediate in the reduction of the hexavalent form, probably the pentavalent form of chromium. Recent results with the trivalent form indicate that other mechanisms may be concerned. In my opinion, all chromium compounds must be regarded as having a carcinogenic effect. This includes soluble, slightly soluble, and the so called insoluble hexavalent compounds, particles of slightly soluble hexavalent and trivalent chromium, and soluble trivalent chromium bound to appropriate ligands. The differences in the activity of the different compounds may be related to their biological availability, and more than one mechanism seems to be involved. Further studies on the microkinetics of the various chromium compounds in different cell systems and in the respiratory tract of experimental animals seem to be urgently required.

Institute of Occupational Health,

T NORSETH

Postboks 8149 Dep,

0033 Oslo 1,

Norway.

\section{References}

1 International Agency for Research on Cancer. Monograph on chromium and chromium compounds. Vol 23. Lyon: IARC, 1980:205-323.

2 Hayes RB. Mortality in chromium chemical workers. A prospective study. Int J Epidemol 1979;8:365-74.

3 Langård S, Norseth T. A cohort study of bronchial carcinomas in workers producing chromate pigments. $\mathrm{Br} J$ Ind Med 1975;32:62-5.

4 Davies JM. Lung cancer mortality of workers in chromate pig- ment manufacture: an epidemiological survey. Journal of the Oil and Colour Chemical Association 1979;62:157-63.

5 Dry Color Manufacturers Association. An epidemiological study of lead chromate plants: final report. Berkeley California: Equitable Environmental Health Inc, 1976.

6 Douglas GR, Bell RDL, Grant CE, Vytsma JM, Bora KD. Effect of lead chromate on chromosome aberration, sister chromatide exchange and DNA damage in mammalian cells in vitro. Mutat Res 1980;77:157-63.

7 Fürst A, Schauder M, Sasmore DP. Tumorigenic activity of lead chromate. Cancer Res 1976;36:1779-83.

8 Langård $\mathrm{S}$. The carcinogenicity of chromium compounds in man and animals. In: Burrows D, ed. Chromium: metabolisms and toxicity. Boca Raton, Florida: CRC Press, 1983:13-30.

9 Nettesheim P, Hanna MG, Doherty DG, Newell RF, Hellman A. Effect of calcium chromate dust, influenza virus and $100 \mathrm{R}$ whole-body $\mathrm{X}$ radiation on lung tumor incidence in mice. J Natl Cancer Inst 1971;47:1129-38.

10 Levy LS, Venitt S. Carcinogenic and mutagenic activity of chromium containing materials. Br J Cancer 1975;32:254-5.

11 Petrilli FL, DeFlora S. Toxicity and mutagenicity of hexavalent chromium on Salmonella typhimurium. Appl Environ Microbiol 1977;33:805-9.

12 Sirover M, Loeb LA. Infidelity of DNA synthesis in vitro: screening for potential metal mutagens or carcinogens. Science 1976;194:1434-6.

13 Warren G, Schultz P, Bancroft D, Bennett K, Abbot EH, Rogers S. Mutagenicity of a series of hexacoordinate chromium (III) compounds. Mutat Res 1981;90:111-8.

14 Kiilunen M, Kivistö H, Ala-Laurila P, Tossavainen A, Aitio A. Exceptional pharmacokinetics of trivalent chromium during occupational exposure to chromium lignosufonate dust. Scand $J$ Work Environ Health 1983;9:265-71.

15 Cupo DY, Wetterhahn KE. Binding of chromium to chromatin and DNA from liver and kidney of rats treated with sodium dichromate and chromium (III) chloride in vivo. Cancer Res 1983;45:1146-51.

16 Norseth T, Alexander J, Langård S. Biliary excretion of chromium in the rat: a role of glutathione. Acta Pharmacol Toxicol 1982;51:450-5.

17 Petrilli FL, DeFlora S. Metabolic deactivation of hexavalent chromium mutagenicity. Mutat Res 1978;54:139-47.

18 Alexander J, Aarseth J, Norseth T. Uptake of chromium by rat liver mitochondria. Toxicology 1982;24:115-22.

19 Elias Z, Poirot O, Schneider O, et al. Cellulas uptake, cytotoxic and mutagenic effects of insoluble chromic oxide in V79 Chinese hamster cells. Mutat Res 1986;169:159-70.

20 Langerwerf ISA, Bakkeren HA, Jongen WMT. A comparison of the mutagenicity of soluble trivalent chromium compounds with that of potassium chromate. Ecotoxical Environ Safety 1985;9:92-100.

21 Hansen K, Stern RM. Welding fumes and chromium compounds in cell transformation assays. J Appl Toxicol 1985;5:306-14.

22 Costa M, Simmons-Hansen J, Bedrossian CWM, Bonura J, Caprioli RM. Phagocytosis, cellular distributions, and carcinogenic activity of particutate nickel compounds in tissue culture. Cancer Res 1981;41:2868-76.

23 Connett PH, Wetterhahn KE. Metabolism of the carcinogen chromate by cellular constituents. Structure and Bonding 1983;53:93-124.

24 Ryberg D, Alexander J. Inhibitory action of hexavalent chromium $(\mathrm{Cr}(\mathrm{VI}))$ on the mitochondrial respiration and a possible coupling to the reduction of $\mathrm{Cr}(\mathrm{VI})$. Biochem Pharmacol 1984;33:2461-6.

25 Cooper JN, Staudt GE, Smalser ML, Settzo LM, Haight GP. Ligand capture in reductions of chromium (VI). Inorganic Chemistry 1973;12:2075-9. 